\title{
Laboratory errors, adverse events and research methodologies: a systematic review
}

\author{
Erros laboratoriais, eventos adversos e metodologias de estudo: uma revisão sistemática
}

Wilson Shcolnik'; Walter Mendes²

\begin{abstract}
Systematic review.

Key words: laboratories; adverse events; medical error; diagnosis error; patient safety; health care quality.
\end{abstract}

\section{INTRODUCTION}

Health care services have benefited from countless technological advances that, if on the one hand contribute to a better quality of life, on the other hand increase the risk of incidents that lead to unnecessary harm to patients: the adverse events (AEs) ${ }^{(20)}$. Health care operating systems are not designed to mitigate errors and avoid the resulting AEs, and inadequate management of these systems has been the object of lots of publications ${ }^{(13)}$.

Although tens of thousands of people around the world suffer harm, many times disabling, and even die because of unsafe acts in health care, little is known about frequency of occurrence, the type of AEs and the contributing factors in hospital environments, and principally, in non-hospital environments. The economic impact of AEs is critical and embarrassing, resulting in costs with the extension of hospital stay, the treatment of the AE or the resulting disabilities, and the litigations ${ }^{(24)}$.

Laboratory medicine is a substantial part of health care systems. It is essential for many decision-making tasks by doctors, nurses and other health professionals, and is related to prevention, diagnosis, treatment, management of illnesses and patients' rehabilitation. Information on laboratory test results helps the practice of evidence-based medicine, for it is contained in the algorithms of clinical guidelines. Laboratory medicine also provides useful information for the management of chronic diseases, allowing monitoring their daily status, the need for drug dose adjustment, and evaluation of the progress achieved from a change in lifestyle. All these pieces of information represent critical components of health care quality and safety ${ }^{(4)}$.

Like other areas of health care, laboratory tests also take place in a complex environment, due to the introduction of information technology and the increasing automation ${ }^{(17)}$. Such complexity may pose problems for clinical laboratories, physicians and patients $^{(22)}$. Despite the low incidence of errors, compared to the large number of laboratory tests daily performed in the world, there are important implications for patient safety ${ }^{(12,17)}$. Literature is extensive about studies on laboratory errors, but few authors focus their consequences. Quantification of AEs related to laboratory errors is a challenging and still-little known subject, due to: (i) study design heterogeneity; (ii) under-reporting in incident notification systems (many times out of fear); (iii) difficulty in associating diagnostic errors with $\mathrm{AEs}^{(2,9,16,23)}$.

First submission on $01 / 04 / 13$; last submission on $01 / 04 / 13$; accepted for publication on $05 / 04 / 13$; published on 20/10/13

1. Pathologist; master's degree in Collective Health from Escola Nacional de Saúde Pública Sergio Arouca da Fundação Oswaldo Cruz (ENSP-Fiocruz); director of accreditation and quality at Sociedade Brasileira de Patologia Clínica (2012-2013); institutional relationship manager of Grupo Fleury.

2. Researcher at ENSP-Fiocruz. 
According the requirements of standard 15189:2003 of the International Organization for Standardization (ISO) - Medical laboratories - particular requirements for quality and competence -, laboratories must adopt investigation processes to identify nonconformities with the procedures or requirements of their quality system. Such processes must be related to corrective and preventive actions $^{(7)}$. According to ISO 22367:2008 (Medical laboratories reduction of error through risk management and continual improvement), risk management is a planned process that is part of both corrective and preventive actions, and is related to stability and predictability of results. It is worth noting that both kinds of action need reports or notifications that depend on the existence and implementation of a culture directed to quality care and patient safety ${ }^{(8)}$.

In clinical laboratories, initiatives to ensure patient safety are justified, what makes the search for answers to the situations encountered in this sector opportune. This work aims at critically reviewing the frequency and the characterization of AEs resulting from laboratory errors, as well as the methodologies employed to assess them.

\section{METHODOLOGY}

A systematic review was conducted to ascertain the AEs resulting from laboratory errors and the methodologies used to evaluate them. Meta-analysis was not used as a statistical method to analyse and summarize the results of the included studies. The following bibliographic databases were used: MEDlars onLINE (MEDLINE), through PubMed interface; COCHRANE, Literatura Latino-Americana e do Caribe em Ciências da Saúde (LILACS); Scientific Electronic Library Online (SciELO); SCOPUS; and WEB of SCIENCE. Access to Excerpta Medica Database (EMBASE) was not possible

In the systematic review, the key words used in Portuguese and English languages are included in the Medical Subject Headings Terms (MeSH), of the U.S. National Library of Medicine (NLM). They were the basis for the search equation, lately adapted for the other used bases (Table 1), and are described as follows: clinical pathology, laboratories, humans, medical error, diagnosis errors, hospital laboratories, clinical laboratory techniques, and combinations among them.

TABLE 1 - Search equation using sources PubMed, Scopus, Web of Science, SciEL0 and LILACS

PubMed Search "clinical" [All Fields] AND pathology[All Fields] OR "clinical chemistry tests/adverse effects" [Mesh Terms] OR "clinical chemistry tests/ organization and administration" [Mesh Terms] OR "clinical laboratory techniques"[All Fields] OR "laboratories" [All Fields] OR "laboratories/ utilization" [All Fields] OR "laboratories, hospital"[All Fields] OR "hospital laboratories" [All Fields] OR "diagnostic services" [All Fields] OR "diagnostic services/adverse effects" [Mesh Terms] OR "chemistry clinical” [All Fields] AND (((((((((("medical errors" [All Fields] OR "medical errors/adverse effects"[All Fields]) OR "diagnostic errors" [All Fields]) OR "diagnostic errors/adverse effects" [All Fields]) OR "blunders" [All Fields]) OR "problems" [All Fields]) OR "errors" [All Fields]) OR "mistake" [All Fields]) OR "diagnostic errors" [All Fields]) OR "diagnostic errors/adverse effects" [All Fields]) OR "medical errors" [All Fields]) OR "medical errors/adverse effects" [All Fields]) AND ((((“"safety management" [All Fields] OR "safety management" [All Fields]) OR "hazard control" [All Fields]) OR "control, hazards"[All Fields]) OR "hazard management" [All Fields]) OR "patient safety" [All Fields]) AND "humans" [MeSH Terms]

Search: laboratory error and clinical impact Limits: only items with links to full text, only items with links to free full text, only items with abstracts, Humans, English, Spanish.

Scopus ABS(clinical AND pathology OR "clinical chemistry tests/adverse effects" OR "clinical chemistry tests/organization and administration" OR "clinical laboratory techniques" OR "laboratories" AND "medical errors" OR "medical errors/adverse effects") AND (exclude (subjarea, "comp") OR exclude (subjarea, "phar") OR exclude (subjarea, "soci") OR exclude (subjarea, "phys") OR exclude (subjarea, "ceng”) OR exclude (subjarea, "engi") OR exclude (subjarea, "neur") OR exclude (subjarea, "psyc") OR exclude (subjarea, "vete") OR exclude ( subjarea, "econ") OR exclude (subjarea, "dent") OR exclude (subjarea, "arts") OR exclude (subjarea, "agri”)) and (exclude (doctype, "le") OR exclude (doctype, "ed") OR exclude (doctype, "no"))

Web of Topic $=($ clinical AND pathology $)$ OR Topic $=($ "clinical chemistry tests/adverse effects" OR "clinical chemistry tests/organization and

Science administration" OR "clinical laboratory techniques" OR "laboratories") AND Topic=("medical errors" OR "medical errors/adverse effects") Timespan=All Years. Databases=SCI-EXPANDED, SSCI, A\&HCI.

SciELO "erro" AND "laboratório" AND "segurança do paciente"

"Patologia clínica" AND "erro"

"Laboratory" AND "patient safety"

"Patologia clínica" AND "segurança do paciente"

"laboratório clínico" AND "segurança do paciente" OR "erro" "laboratório clínico" AND "evento adverso" "laboratório clínico" AND "erro" "erro laboratorial"; "laboratório hospitalar" AND "segurança do paciente" OR "erro"

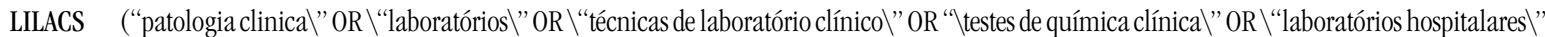
$\mathrm{OR} \backslash$ "serviços de diagnóstico\” OR\"química clínica\”) AND (“erros médicos\” OR \"erros de diagnóstico〉") 
Non-MeSH terms were also used in the searches, for being frequently present in recent publications on patient safety: patient safety, adverse events, laboratory medicine, and total or complete testing process.

The search was not limited by publication date, and the last search occurred in April, 2011. A documentary research was also conducted, in related websites and in bibliographic references of the selected documents.

The selection criteria included texts that presented the relationship between laboratory error and patient safety, followed by at least one of the variables: (i) detection method and/or incident communication; (ii) period of data collection; (iii) type of studied clinical laboratory (public or private, emergency, university, etc.); (iv) technical sector of the involved clinical laboratory; (v) number of studied patients or exams; (vi) type of studied patients (inpatients or outpatients); (vii) phase of the laboratory process involved in the error; (viii) number of incidents found; (ix) types of incidents; (x) frequency of laboratory error; and (xi) proportion of avoidable AEs.

The criteria excluded texts: (i) in letter format, editorials, news, commentaries by professionals, case reports and articles with no abstract, published in languages different from Portuguese, English and Spanish; (ii) concerning exclusively genetic or histopathological laboratory tests, or studies conducted in laboratories dedicated exclusively to these exams; (iii) related exclusively to blood banks or data related to this sector handled in other studies; (iv) presenting data related to other complementary non-laboratory tests; (v) that were duplicated; and (vi) not presenting information about the effect of laboratory errors on patient safety.

For text selection, the assessment of titles and abstracts identified in the initial search was made by two researchers (physicians with experience in the areas of laboratory care and patient safety) in an independent form, rigorously applying the inclusion and exclusion criteria defined in the study protocol. Articles and texts were selected in two phases: 1) evaluation of titles and abstracts of all identified studies; 2) evaluation of the full text. Divergences were resolved by consensus. When consensus was not reached, the study was included for full reading. A thorough reading of the selected texts, as well as of those obtained through research in websites and bibliographic references, was done exclusively by the main researcher, using the same inclusion and exclusion criteria.

\section{RESULTS}

The initial search in the cited databases resulted in the retrieval of 230 texts. After the reading of titles and abstracts, and the application of inclusion, exclusion and selection criteria, 90 texts remained. of this total, 22 duplicate texts were excluded, and 68 remained for complete reading, to which four new texts were added, selected from bibliographical references. After review, 63 were excluded for being studies of organizational structure and laboratories of other specialties, or for not satisfying the presented criteria. Nine texts remained that were the result of this systematic review. Each text corresponded to a study description.

The nine studies were:

1) Problems in laboratory testing in primary care - that examined the frequency and the characteristics of laboratory problems in primary care and their impacts on health care ${ }^{(11)}$;

2) Mistakes in a stat laboratory: types and frequency - that evaluated the frequency and the types of errors found in a stat laboratory, by monitoring four departments (internal medicine, nephrology, surgery and intensive care unit) ${ }^{(19)}$;

3) Adverse events and deaths associated with laboratory error at a hospital - Pennsylvania - study of the Centers for Disease Control and Prevention (CDC) that presents the results of an investigation of two deaths ${ }^{(5)}$;

4) A physician-based voluntary reporting system for adverse events and medical errors - that aimed at the creation of a voluntary reporting method for the identification of real and potential AEs among inpatients ${ }^{(24)}$

5) Classifying laboratory incident reports to identify problems that jeopardize patient safety - that evaluated the errors and AEs of a laboratory incident report classification system $^{(1)}$;

6) Clinical impact associated with corrected results in clinical microbiology testing - that describes the strategy used to identify and characterize the clinical impact associated with corrected results of clinical microbiology tests ${ }^{(28)}$;

7) Errors in a stat laboratory: types and frequencies 10 years later - that repeated the study design used by Plebani in $1997^{(6)}$;

8) Characterizing cases associated with corrected reports in hematology and coagulation - that described the strategy to determine if screening criteria could be applied to corrected results of hematology and coagulation testing, to identify association with adverse clinical impacts ${ }^{(10)}$;

9) The development of a system for reporting, classification and grading of quality failures in the clinical biochemistry laboratory - that described a system to report, classify and 
grade the severity of quality failures in actual and potential adverse impacts ${ }^{(12)}$.

The objectives, used methodologies, sectors and types of the studied clinical laboratories, the period of time used for data collection, the type and size of the studied population, the AEs, the clinical impacts and the preventability of the AEs encountered in the selected studies are presented, respectively, by author and year of publication in Tables 2, 3 and $\mathbf{4}$.

\section{DISCUSSION}

Measuring frequency and characterizing AEs resulting from laboratory errors is a challenging subject. The variety of definitions of error, incident, $\mathrm{AE}$, and the methodology used in each study were the factors that may have contributed to the varied results found in this review.

According to the International Classification for Patient Safety (ICPS), developed by the World Health Organization (WHO)

\begin{tabular}{|c|c|c|c|}
\hline Author/year & Study objective & Study method & Laboratory sector/type \\
\hline Nutting, 1996 & $\begin{array}{l}\text { Examine the frequency and the } \\
\text { characteristics of incidents with laboratory } \\
\text { tests and their impacts on patient care }\end{array}$ & $\begin{array}{l}\text { Prospective study of laboratory incidents } \\
\text { voluntarily reported by physicians, with } \\
\text { detailed description of impacts on patient } \\
\text { care }\end{array}$ & $\begin{array}{l}\text { Laboratories serving primary care } \\
\text { physicians' offices }\end{array}$ \\
\hline Plebani, 1997 & $\begin{array}{l}\text { Evaluate the frequency and types of stat } \\
\text { laboratory errors }\end{array}$ & $\begin{array}{l}\text { Identify the critical steps to devise the } \\
\text { corrective strategy. Prospective study of } \\
\text { laboratory test results suspected of errors. } \\
\text { Discussion with clinician and review by a } \\
\text { clinical pathologist }\end{array}$ & $\begin{array}{l}\text { Stat laboratory (biochemistry, hematology, } \\
\text { coagulation, immunology). } \\
\text { University hospital laboratory }\end{array}$ \\
\hline $\mathrm{CDC}, 2001$ & $\begin{array}{l}\text { Investigate deaths associated with } \\
\text { laboratory errors }\end{array}$ & $\begin{array}{l}\text { Retrospective study of laboratory test results } \\
\text { and patient screening, after two deaths by } \\
\text { hematology/coagulation }\end{array}$ & Hospital laboratory \\
\hline Weingart, 2001 & $\begin{array}{l}\text { Develop a voluntary reporting method to } \\
\text { identify AEs or PAEs in inpatients }\end{array}$ & $\begin{array}{l}\text { Mixed (interview and voluntary reporting } \\
+ \text { codification and classification by health } \\
\text { professional }+ \text { review of medical records } \\
\text { and incident reportings) }\end{array}$ & $\begin{array}{l}\text { Sector of the hospital laboratory was not } \\
\text { previously determined. } \\
\text { University hospital laboratory }\end{array}$ \\
\hline Astion, 2003 & $\begin{array}{l}\text { Evaluate the laboratory incident report } \\
\text { classification system }\end{array}$ & $\begin{array}{l}\text { Retrospective study of incident report } \\
\text { evaluation by physicians and laboratory } \\
\text { staff }+ \text { application of classification }\end{array}$ & $\begin{array}{l}\text { Laboratory sector was not previously } \\
\text { determined. } \\
\text { University hospital laboratory }\end{array}$ \\
\hline Yuan, 2005 & $\begin{array}{l}\text { Evaluate the clinical impact of laboratory } \\
\text { errors related to microbiology testing }\end{array}$ & $\begin{array}{l}\text { Prospective study of corrected laboratory } \\
\text { tests in three phases: evaluation of corrected } \\
\text { report by infectologist, medical record } \\
\text { review, and detailed evaluation of care } \\
\text { result that included interview with clinician }\end{array}$ & Microbiology - two medical centers \\
\hline Carraro, 2007 & $\begin{array}{l}\text { Compare laboratory error data after } 10 \\
\text { years, in the same clinical context and } \\
\text { study design }\end{array}$ & $\begin{array}{l}\text { Prospective study of laboratory test results } \\
\text { suspect of errors, discussion with clinician } \\
\text { and review by a clinical pathologist }\end{array}$ & $\begin{array}{l}\text { Stat laboratory (biochemistry, hematology, } \\
\text { coagulation, immunology). } \\
\text { University hospital laboratory }\end{array}$ \\
\hline Natividad, 2007 & $\begin{array}{l}\text { Test screening criteria of adverse clinical } \\
\text { impact associated with corrected laboratory } \\
\text { test results }\end{array}$ & $\begin{array}{l}\text { Prospective study of screening of corrected } \\
\text { laboratory test results: review of medical } \\
\text { records and laboratory records + interview } \\
\text { with the involved health professor }\end{array}$ & $\begin{array}{l}\text { Hematology/coagulation. } \\
\text { University hospital laboratory }\end{array}$ \\
\hline 0'Kane, 2008 & $\begin{array}{l}\text { Develop a structured approach to identify, } \\
\text { classify and grade "quality failures" } \\
\text { in chemistry laboratory that may be } \\
\text { incorporated to routine }\end{array}$ & $\begin{array}{l}\text { Prospective study of questionnaires on } \\
\text { quality failures answered by a laboratory } \\
\text { professional followed by investigation of } \\
\text { impact on patient care (conducted by a } \\
\text { laboratory senior professor along with } \\
\text { clinical staff) and classification of quality } \\
\text { failures by "actual" or "potential" impact } \\
\text { severity }\end{array}$ & $\begin{array}{l}\text { Biochemistry. } \\
\text { General hospital laboratory }\end{array}$ \\
\hline
\end{tabular}




\begin{tabular}{|c|c|c|}
\hline Author/year & Data collection period & Size of the study population \\
\hline Nutting, 1996 & 6 months & Reporting by 124 physicians in 49 outpatient clinics - 160,714 visits \\
\hline Plebani, 1997 & 3 months & 40,490 tests in four departments (internal medicine, nephrology, surgery, and ICU) \\
\hline $\mathrm{CDC}, 2001$ & 50 days & 2,146 tests \\
\hline Weingart, 2001 & 3 months & $\begin{array}{l}\text { Three studied services: coronary care unit with } 30 \text { beds, oncology with } 18 \text { beds, and } \\
\text { ICU with } 12 \text { beds - total of } 987 \text { patients and } 88 \text { incidents }\end{array}$ \\
\hline Astion, 2003 & 16 months & Study of 129 incident reports \\
\hline Yuan, 2005 & 9 months & Out of 164,000 samples submitted to testing, 480 required correction (0.3\%) \\
\hline Carraro, 2007 & 3 months & 51,746 tests of four departments (internal medicine, nephrology, surgery and ICU) \\
\hline Natividad, 2007 & 11 months & 614 corrected results \\
\hline 0'Kane, 2008 & 19 months & 468,285 test orders; 397 searches in quality reports \\
\hline
\end{tabular}

ICU: intensive care unit; CDC: Centers for Disease Control and Prevention.

\begin{tabular}{|c|c|}
\hline Author/year & Study results \\
\hline \multirow[t]{2}{*}{ Nutting, 1996} & $\begin{array}{l}27 \% \text { of incidents affected patient care. } 50 \% \text { of incidents had their impact described and revealed that } 45.5 \% \text { significantly affected diagnosis } \\
\text { and/or treatment; the others caused smaller effects }\end{array}$ \\
\hline & $\begin{array}{l}\text { Impacts on health care: recollection; cervical cancer screening; determination of prothrombin time; false-negative HIV serology; false } \\
\text { positive pregnancy test; delayed results for stat potassium test; false-negative urine culture; delayed results for stool culture; unnecessary } \\
\text { hospital admissions }\end{array}$ \\
\hline \multirow[t]{2}{*}{ Plebani, 1997} & $\begin{array}{l}74 \% \text { of errors did not affect patients and } 26 \% \text { altered the "effects on patient outcome" (in 19\% further investigation was necessary; } 6.4 \% \\
\text { caused inappropriate care or modification of therapy) }\end{array}$ \\
\hline & $\begin{array}{l}\text { "Effects on patient outcome": further investigation or inappropriate care or modification of therapy, which caused unjustified increase in } \\
\text { costs - inappropriate blood transfusion, changes in heparin infusion; inappropriate electrolyte infusion solution; inappropriate change } \\
\text { in digoxin therapy }\end{array}$ \\
\hline \multirow[t]{2}{*}{ CDC, 2001} & From the investigation of two deaths, 2,146 revised tests were verified to have calculation errors \\
\hline & AEs: deaths \\
\hline \multirow[t]{3}{*}{ Weingart, 2001} & $\begin{array}{l}\text { AEs associated with laboratory errors were not observed. Forty-eight PAEs ( } 54.5 \% \text { of total incidents and } 4.9 \% \text { of hospital admissions). } \\
\text { Laboratory errors resulted from } 8 \text { PAEs ( } 16.7 \% \text { of total PAEs or } 9 \% \text { of total incidents) }\end{array}$ \\
\hline & PAEs $=$ near miss \\
\hline & Delays in result releases, diagnosis and treatment, difficulties in hospital discharge \\
\hline \multirow[t]{5}{*}{ Astion, 2003} & AEs - 6 (5.4\%); PAEs - $122(95 \%) ;$ PAE + AE - $1(1 \%)$ \\
\hline & Most common AE: delayed results in 110 cases (85\%); recollection in 51 cases (40\%); phlebotomy-related injuries in 7 cases $(5 \%)$ \\
\hline & Actual AE: delayed results, recollection); release of incorrect results to physicians; phlebotomy-related injuries \\
\hline & $\begin{array}{l}\text { PAEs impacts: delay in thyroglobulin test in the outpatient setting; relabeling of hospital sample, after losing identification; physician } \\
\text { questioned low hemoglobin and hematocrit values in the ambulatory setting, with recollection and obtainment of results within the } \\
\text { reference range; turnaround time of } 2 \mathrm{~h} \text { for stat coagulation tests in the ICU; } 3 \text {-day delay receiving positive blood culture result (Klebsiella } \\
\text { pneumoniae) for a patient undergoing dialysis, causing untreatment for } 2 \text { days and mistreatment for } 1 \text { day }\end{array}$ \\
\hline & $\begin{array}{l}94 \text { preventable incidents (preventability scale of } 1 \text { [definitely not preventable] to } 5 \text { [definitely preventable]): 1) } 3 \text { incidences (2\%); } \\
\text { 2) } 15 \text { incidences (12\%);3) } 9 \text { incidences (7\%); 4) } 32 \text { incidences (25\%); 5) } 53 \text { incidences ( } 41 \%) \text {; unable to determine) } 17 \text { incidences (13\%) }\end{array}$ \\
\hline \multirow[t]{4}{*}{ Yuan, 2005} & $301(62.7 \%)$ of corrected results were not considered with significant clinical impact \\
\hline & $\begin{array}{l}\text { Of the } 154 \text { cases }(32.1 \%) \text { indicated for physician interview, } 32(6.7 \%) \text { cases of corrected results were associated with adverse clinical } \\
\text { impact. Delayed therapy in } 19(54 \%) \text {; inappropriate therapy in } 8(25 \%) \text {; unnecessary therapy in } 8(25 \%) \text {; unnecessary invasive test or } \\
\text { procedure in } 1(3.1 \%) \text {; transient morbidity < } 1 \text { week) in } 5(15.6 \%) \text {; morbidity > } 1 \text { week) in } 1(3.1 \%) \text {; increased level of care in } 4(12.5 \%)\end{array}$ \\
\hline & $\begin{array}{l}\text { AEs: Delayed therapy; inappropriate or unnecessary therapy; unnecessary invasive test or procedure; transient morbidity; increased level } \\
\text { of care }\end{array}$ \\
\hline & Preventability in 28 cases $(87.5 \%)$ \\
\hline
\end{tabular}




\begin{tabular}{|c|c|}
\hline Author/year & Study results \\
\hline \multirow[t]{4}{*}{ Carraro, 2007} & 121 errors $(75.6 \%)$ produced no effect on patients, while $39(24.4 \%)$ had negative impact on patient care \\
\hline & AEs: admission to ICU; recollection; inappropriate transfusion; further inappropriate investigations \\
\hline & $\begin{array}{l}\text { Patient outcome: admission to ICU }-1 \text { case }(0.6 \%) \text {; unnecessary transfusion }-2(1.3 \%) \text {; further investigation }-9(5.6 \%) \text {; laboratory } \\
\text { test repetition } 27(16.9 \%)\end{array}$ \\
\hline & Preventability in $73.1 \%$ \\
\hline \multirow[t]{3}{*}{ Natividad, 2007} & $\begin{array}{l}614 \text { corrected results; } 97(15.8 \%) \text { cases were considered positive (met } 1 \text { or more screening criteria), and } 517(84.2 \%) \text { negative regarding } \\
\text { screening. Of the } 97 \text { corrected results, } 8(8.2 \%) \text { were associated with adverse clinical impacts }\end{array}$ \\
\hline & $\begin{array}{l}\text { Adverse clinical impact: } 5 \text { cases involved increased level of care; } 2 \text { involved unnecessary treatments; } 1 \text { involved untreatment; and } 1 \\
\text { involved delay in the appropriate treatment }\end{array}$ \\
\hline & Preventability - $59(60.8 \%)$ preventable; 27 (27.8\%) unpreventable and $11(11.3 \%)$ not determined \\
\hline \multirow[t]{7}{*}{ 0’Kane, 2008} & $75 \%$ of quality failures did not have negative impact on patient care \\
\hline & Correlation between severity grade and actual and potential quality failures*: \\
\hline & - score of 1 - increase of actual failures in $72.7 \%$ and potential failures in $0.3 \%$ \\
\hline & - score of 2 - increase of actual failures in $6.9 \%$ and potential failures in $11.6 \%$ \\
\hline & - score of 3 - increase of actual failures in $20.8 \%$ and potential failures in $15.9 \%$ \\
\hline & - score of 4 - increase of actual failures in $0 \%$ and potential failures in $6.2 \%$ \\
\hline & - score of 5 - increase of actual failures in $0 \%$ and potential failures in $66 \%$ \\
\hline
\end{tabular}

*Severity score 1 corresponds to minimum severity; 5 , to maximum severity

AE: adverse event; PAE: potential adverse event; ICU: intensive care unit.

through the Patient Safety Program, errors, failures or problems in care are termed incidents ${ }^{(25-27)}$. Incidents may or may not affect the patient; in case they do, they may or may not cause a real harm. If it does not affect the patient, it is considered a near miss; if it does affect the patient, there may be an "incident with no harm to the patient" or an "incident with harm to the patient", in this case, known as $\mathrm{AE}^{(27)}$.

In relation to $\mathrm{AE}$ measurement and characterization, three elements may influence results: (i) the subjectiveness of the professional who judges if the patient suffered harm resulting from an error during care; (ii) the used methodology; (iii) the difficulty in associating laboratory errors with harm to patients ${ }^{(2,9,16,19,23)}$.

According to the definitions used in the selected studies, concepts of laboratory errors are closer to the standards of ISO 22367:2008. However, $\mathrm{AE}$ is not considered in this group of norms ${ }^{(8)}$.

In Nutting's study ${ }^{(11)}$, laboratory errors are considered "problems in laboratory tests". Plebani ${ }^{(19)}$ and Carraro ${ }^{(6)}$ referred to laboratory errors defining them as "any defect during the entire testing process, from ordering tests to reporting results, that influenced in any way the quality of the laboratory service".

The term incident was associated with laboratory errors in $\mathrm{CDC}^{(5)}$ and Weingart's ${ }^{(2)}$ studies. Astion ${ }^{(1)}$ used the term incident to qualify the reporting system in which he developed his study (laboratory incident report classification system).
Yuan ${ }^{(28)}$ referred to "error in microbiology testing", and Natividad ${ }^{(10)}$ to "laboratory errors". O'Kane ${ }^{(12)}$ referred to "quality failures", defining them as "any failure to meet the required quality output needed for optimal patient care, anywhere in the pathway from test selection to the appropriate interpretation by the clinician" that had impact on patient care.

The results presented a great variety of terms and meanings.

Nutting ${ }^{(11)}$ called the consequences of errors "impacts on health care"; Plebani ${ }^{(19)}$ and Carraro $^{(6)}$ referred to "patient outcome". The $\mathrm{CDC}^{(5)}$ mentioned EA, and Weingart ${ }^{(24)}$, as well as Astion $^{(1)}$, used a definition of AE similar to that by the Harvard study ${ }^{(3)}$, which is the most frequently used definition in studies on patient safety: $\mathrm{AE}$ is "non-intentional harm that results in death, temporary or permanent disability, or prolonged hospital stay". $\mathrm{AE}$ in Astion's ${ }^{(1)}$ study was defined as "an injury to a patient rather than by a disease process, in which the injury resulted in disability or prolonged hospital stay".

Yuan $^{(28)}$ referred to adverse clinical impact in some patients that had their test results corrected. Natividad ${ }^{(10)}$ called the result in patients as "adverse clinical impact", considering the following situations: hospitalization of outpatients, prolonged hospital stay, increase in care level (need of new visits, required follow-up care), failure to receive necessary treatment, unnecessary treatment, transient or lasting morbidity, and death. Like the studies by other authors, Natividad's ${ }^{(10)}$ considered the incidents causing the harm 
transient or lasting morbidity or death, while other incidents did not have, necessarily, an associated harm.

0 'Kane ${ }^{(12)}$ mentioned impact in patient care. Weingart ${ }^{(24)}$ also described "potential AEs". In the same line, "potential AE", according to Astion" ${ }^{(1)}$, was defined as "error or incident that produced no injury, but had the clear potential to do so. It may have been intercepted before producing harm or, luckily, may have reached the patient but produced no injury". Consequences, in this case, were called "specific and potential impacts on patient".

AEs classification into actual and potential, therefore, was made in three studies ${ }^{(1,12,24)}$. O'Kane ${ }^{(12)}$ considered the existence of a system for reporting quality failures important and desirable, to verify not only actual AEs, but also the potential ones, grading their severity, to help prioritize corrective actions and monitor the overall performance of the clinical laboratory. A quality failure may not always affect the patient, creating an actual $\mathrm{AE}$, but the near miss contributes to identify the fragility of systems, which may, in the future, lead to a preventable AE. According to $0^{\prime} \mathrm{Kane}^{(12)}$, it is uncommon for an individual isolated failure in laboratory quality to result in patient incidents, but the potential for this to happen is high. Astion ${ }^{(1)}$ and Weingart ${ }^{(24)}$, using the concepts of AEs and potential AEs, differentiated incident with harm from incident without harm, or near miss.

Analysis of incident report was done in three studies. Several authors highlighted the importance of precision in data collection about incidents. Data from voluntary reporting systems have been used to study AEs, however, as the majority of incidents are not reported (many times because of fear by those who should do it), it is necessary to associate other methodologies.

The investigation method of the surveillance type performed by CDC based itself in the Safe Medical Devices Act, published in 1990, in the United States of America (USA). It requires hospitals and other health care services to report, to the Food and Drug Administration (FDA), deaths or injuries associated with the use medical devices, including those caused by laboratory trials and/or used equipment ${ }^{(5)}$. The method is considered adequate to identify $\mathrm{AEs}^{(21)}$.

The authors who presented studies with a method based on the correction of test results, Yuan ${ }^{(28)}$ and Natividad ${ }^{(10)}$, considered the method reproducible and promising for employment in clinical laboratories. Yuan ${ }^{(28)}$ pointed out limitations on the study: (i) reports of result correction do not comprise many cases of potential AEs related to laboratory tests, and they seem not to detect AEs that happen by chance; (ii) the detection method through corrected test results may have a bias in detecting analytical errors, instead of pre- or post-analytical ones. The author concludes that this method must be used along with others that collect data from sources such as incident notification reports, medical complaints and other forms of cooperation with care teams. The advantage of Natividad's ${ }^{(1)}$ study in relation to Yuan's ${ }^{(28)}$ is the error screening phase, when the intervention of general practitioners is not necessary to assess the impact on the patient, making investigation easier.

Interviews, discussion, and questionnaire filling by doctors were used in eight of the nine selected studies, what may indicate a tendency to associate a method in which the medical team and other professionals are heard in order to evaluate AEs resulting from laboratory errors. This means emphasizing the importance of, without neglecting the analytical phase, invest in the involvement of teams from outside the clinical laboratory, which act in the preand post-analytical processes. Such interaction allows obtaining information on the impact of incidents that would hardly be known by the laboratory staff and may be explained by the complex processes occurring in the borderline between laboratory and clinic $^{(18)}$. To that end, it is essential to allocate laboratory professionals with skills and knowledge to deal with the theme, aiming atcontinuous improvement. This cooperation practice may be introduced in outpatient (independent) and hospital laboratories, especially in hospitals where laboratory support tends to be more structured, and there is close proximity and access between the laboratory team and medical teams and other health care professionals.

It is opportune to consider that four studies were conducted in laboratories of university hospitals, that is, in an environment more propitious to research and different from that of independent laboratories or those that serve an outpatient clientele. Weingart's ${ }^{(24)}$ study counted on the participation of revisors and information management, besides a team qualified to conduct the technical clinical analysis of the incidents, and involved a structure that is not always available in laboratories out of a university setting.

Due to differences in methodology and the definition of incident in each study, results were quite disparate. Yuan ${ }^{(28)}$ observed that it is not always possible to separate the impact of laboratory error from the effects of the patient's illness condition. Also, results of clinical impacts may be underestimated, because many doctors find it difficult to conduct evaluations of impacts caused by the incident and tend to be conservative. According to Yuan ${ }^{(28)}$, doctors consider it easier to identify objective facts, such as delay in treatment, than others, such as morbidity increase, whose evaluation is more subjective.

In the review conducted by Bonini ${ }^{(2)}$, there was an effort to classify findings to better present results. Although the considered original descriptions have referred to the frequency of impacts or AEs, some results were partially recalculated to allow comparison among them. 
Astion ${ }^{(1)}$ presented a result in which there was occurrence of $5.4 \%$ of AEs. The deaths that caused the investigation by $\mathrm{CDC}^{(5)}$ corresponded to $0.09 \%$ of the investigated incidents. Nutting ${ }^{(11)}$ reported that $27 \%$ of the total incidents caused impact on health care. It is necessary to consider that out of 49 incidents that affected health care, just half represents $13.3 \%$ of total incidents, which were described in detail. Plebani ${ }^{(19)}$ related a total of $26 \%$ of effects on patient outcome. Weingart ${ }^{(24)}$ did not report AEs related to laboratory error. Yuan ${ }^{(28)}$ stated that $6.7 \%$ of total investigated incidents had a clinical impact as consequence. Carraro ${ }^{(6)}$ described $24.4 \%$ of errors related to care outcome, and Natividad ${ }^{(10)}$ reported $1.3 \%$ of adverse clinical impact on the total incidents. O'Kane ${ }^{(12)}$ did not reveal frequency, but the relationship between quality failures and the severity of actual adverse impacts and worse potential outcomes. Adverse potential impacts were associated with higher proportions of quality failure.

In just four studies, all published after 2003, preventability rates were found, with high proportions of preventable AEs described $^{(1,6,10,28)}$. Yuan ${ }^{(28)}$ and Natividad ${ }^{(10)}$, who presented studies with a method based on test result correction, showed that this method may reveal a significant number of avoidable AES.

Except for deaths and transient morbidity or increased care level that, according to $\mathrm{WHO}^{(27)}$ taxonomy must be classified as AEs, the other events would deserve a more detailed investigation, what would permit to classify them as incident with no harm or even a near miss.

Despite the difficulties, the selected studies confirm the low frequency of AEs resulting from laboratory errors. This happens possibly because of barriers existing during laboratory process ${ }^{(14,15,17)}$.

The methods used in the studies did not permit a comparison of results. Even in the studies of Plebani ${ }^{(19)}$ and Carraro ${ }^{(6)}$, who used the same technology, in an interval of ten years, there is a limitation on the contrast due to the different existing conditions and the technological evolution that took place in the period ${ }^{(6)}$. Among the different characteristics, not always informed in all the studies, these stood out: (i) use, or not, of laboratory teams suited to collect hospital samples; (ii) automation levels of laboratory processes; (iii) used analytical instruments; (iv) composition of the technical teams (formation, time of experience); (v) consideration, or not, of incidents detected and corrected before result liberation; (vi) consideration of all phases of the laboratory process; (vii) logistics used to transport samples to laboratory; (viii) available technological resources (electronic ordering of tests, interface between analytical systems and laboratory computer system, automatic validation for result release).

It is necessary to consider other limitations observed in the selected studies to compare them. Studies were conducted in three different countries (Italy, USA, and United Kingdom), and in different times, besides having included clinical laboratories that had distinct resources and that, in general, were not described in detail. It is also necessary to consider the regulatory requirements of each country, which may have changed during the years when the studies were published. Such requirements, as one can foresee, directly affect laboratory practice and, consequently, the quality of the reported test results. Hospital structures where clinical laboratories were inserted were not described in detail, what may also limit comparisons.

\section{CONCLUSION}

The results of this systematic review demonstrated that there was no significant increase of studies associating laboratory errors with AEs, years after publication on the subject by Bonini $e t a l$. in $2002^{(2)}$

Lack of standardized taxonomy and the several methodologies used by authors to identify and classify incidents implied the obtainment of different results, of difficult comparison, and did not enable the determination of the most effective method to assess frequency and characteristics of AEs resulting from laboratory errors. Despite these limitations, the selected studies confirmed the low frequency of AEs resulting from laboratory errors.

Even considering this finding, the investigation of incidents associated with laboratory errors must keep being stimulated because, besides harm to patients, they may bring other impacts and damages to the health system.

According to Yuan ${ }^{(2)}$ and other studies cited here, the participation of outside laboratory staff and physicians in the investigation of AEs resulting from laboratory errors is fundamental, because they have information not always available to laboratory teams. This allows the obtainment of data on the impact of incidents that would hardly be known by the laboratory team.

High preventability rates justify risk management investments aimed at identifying and reducing laboratory errors and the occurrence of adverse events resulting from them.

According to norm ISO 22367:2008 ${ }^{(8)}$, identification of errors or incidents must be made through reviews of internal audits, incident notification reports, improvement opportunities and prospective processes of risk analysis. Further investigations aimed at increasing knowledge about impacts of laboratory errors on patient safety must suit concepts on actual and potential AEs, as well as their severity, to the International Classification for Patient Safety of WHO. 


\section{RESUMO}

Revisão sistemática.

Unitermos: laboratórios; eventos adversos; erro médico; erros de diagnóstico; segurança do paciente; qualidade em saúde.

\section{REFERENCES}

1. ASTION, M. et al . Classifying laboratory incident reports to identify problems that jeopardize patient safety. Am J Clin Pathol, v. 120, p. 18-26, 2003 .

2. BONINI, P. et al. Errors in laboratory medicine. Clin Chem, v. 48, n. 5 , p. 691-8, 2002.

3. BRENNAN, T. A.; LEAPE, L. L.; LAIRD, N. M. Incidence of adverse events and negligence in hospitalized patients: results of the Harvard Medical Practice Study I. N Engl J Med, v. 324, n. 6, p. 370-6, 1991.

4. CDC. Centers for Disease Control and Prevention. Laboratory medicine: a national status report. Chapter I. The value of laboratory medicine to health care, 2007. Available at: <http://wwwn.cdc.gov/dls/bestpractices/ references.aspx>. Accessed on: 18 Feb. 2011.

5. CDC. Centers for Disease Control and Prevention. Public health dispatch: adverse events and deaths associated with laboratory error at a hospital - Pennsylvania. MMWR Weekly, v. 50, n. 33, p. 10-1, 2001.

6. CARRARO, P.; PLEBANI, M. Errors in a stat laboratory: types and frequencies 10 years later. Clin Chem, v. 53, n. 7, p. 1338-42, 2007.

7. ISO 15189:2003. Medical laboratories. Particular requirements for quality and competence. 2003.

8. ISO/TS 22367:2008. Medical laboratories: reducing error through risk management and continual improvement: complementary element, 2008.

9. LEAPE, L. Scope of problem and history of patient safety. Obstet Gynecol Clin NAm, v. 35, n. 1, p. 1-10, 2008.

10. NATIVIDAD, C. E. Characterizing cases associated with corrected reports in hematology and coagulation. AACC San Diego, CA July 15-19, topic hematology/coagulation-presentation, number C-118, 2007.

11. NUTTING, P. A. et al. Problems in laboratory testing in primary care. JAMA, v. 275, n. 8, p. 635-9, 1996.

12. O'KANE, M. J.; LYNCH, P. L.; Mc GOWAN, N. The development of a system for the reporting, classification and grading of quality failures in the clinical biochemistry laboratory. Ann Clin Biochem, v. 45, pt. 2, p. 129-34, 2008

13. OKORODUDU, A. Efficacy of clinical laboratory: therapeutic TAT, safety, and medical errors. Clin Biochem, v. 42, n. 4-5, p. 300, 2009.
14. PLEBANI, M. The detection and prevention of errors in laboratory medicine. Ann Clin Biochem, v. 47, pt. 2, p. 101-10, 2010.

15. PLEBANI, M.; LIPPI, G. To err is human. To misdiagnose might be deadly. Clin Biochem, v. 43, n. 1-2, p. 1-3, 2010.

16. PLEBANI, M. Errors in laboratory medicine and patient safety: the road ahead. Clin Chem Lab Med, v. 45, n. 6, p. 700-7, 2007.

17. PLEBANI, M. Exploring the iceberg of errors in laboratory medicine. Clin Chem Acta, v. 404, n. 1, p. 16-23, 2009.

18. PLEBANI, M. The CCLM contribution to improvements in quality and patient safety. Clin Chem Lab Med, v. 51, n. 1, p. 39-46, 2013.

19. PLEBANI, M.; CARRARO, P. Mistakes in a stat laboratory: types and frequency. Clin Chem, v. 43, n. 8, p. 1348-51, 1997.

20. RUCIMAN, W. B. et al. Towards an international classification for patient safety: key concepts and terms. Int J Qual Health Care, v. 2, n. 1, p. 18-26, 2009.

21. THOMAS, E. J.; PETERSEN, L. A. Measuring errors and adverse events in health care.J Gen Intern Med, v. 18, n. 1, p. 61-7, 2003.

22. WAGAR, E. A.; YUAN, S. The laboratory and patient safety. Clin Lab Med, v. 27, n. 4, p. 909-30, 2007.

23. WANG, S. Corrections of clinical chemistry test results in a laboratory information system. Arch Pathol Lab Med, v. 128, n. 8, p. 890-2, 2004.

24. WEINGART, S. N. et al. A physician-based voluntary reporting system for adverse events and medical errors. J Gen Intern Med, v. 16, n. 12, p. 809-14, 2001.

25. WHO. World Health Organization. Patient Safety, 2009. Available at: $<$ www.who.int/patientsafety/en/>. Accessed on: 7 Jan. 2010.

26. WHO. World Health Organization, 2008. Available at: <www.who.int/ patientsafety/research>. Accessed on: 23 Feb. 2011.

27. WHO. World Health Organization. Final report for the conceptual framework for the international classification for patient safety. Version 1.1. 2009. Available at: <www.who.int/patientsafety/taxonomy/en/> Accessed on: 20 Feb. 2011.

28. YUAN, S. et al. Clinical impact associated with corrected results in clinical microbiology testing. J Clin Microbiol, v. 43, n. 5, p. 2188-93, 2005.

\section{MAILING ADDRESS}

\section{Wilson Shcolnik}

Av. Epitácio Pessoa, 5088, apto 401; Lagoa; Rio de Janeiro-RJ, Brazil; e-mail: wilson.shcolnik@grupofleury.com.br. 